\title{
Evaluation of Rehabilitation of Memory in Neurological Disabilities (ReMiND): a randomized controlled trial
}

\author{
Roshan das Nair and Nadina B Lincoln
}

\begin{abstract}
Objective: The evidence for the effectiveness of memory rehabilitation is inconclusive. The aim was to compare the effectiveness of two group memory rehabilitation programmes with a self-help group control.
\end{abstract}

Design: Single-blind randomized controlled trial.

Participants: Participants with memory problems following traumatic brain injury, stroke or multiple sclerosis were recruited from community settings.

Interventions: Participants were randomly allocated, in cohorts of four, to compensation or restitution group treatment programmes or a self-help group control. All programmes were manual-based and comprised two individual and ten weekly group sessions.

Main measures: Memory functions, mood, and activities of daily living were assessed at baseline and five and seven months after randomization.

Results: There were 72 participants (mean age 47.7, SD 10.2 years; 32 men). There was no significant effect of treatment on the Everyday Memory Questionnaire $(P=0.97)$. At seven month the mean scores were comparable (restitution 36.6, compensation 41.0, self-help 44.1). However, there was a significant difference between groups on the Internal Memory Aids Questionnaire $(P=0.002)$. The compensation and restitution groups each used significantly more internal memory aids than the self-help group $(P<$ $0.01)$. There were no statistically significant differences between the groups on measures of mood, adjustment and activities of daily living $(P>0.05)$.

Conclusions: There results show few statistically significant effects of either compensation or restitution memory group treatment as compared with a self-help group control. Further randomized trials of memory rehabilitation are needed.

\section{Keywords}

Memory, cognitive impairment, randomized controlled trial, group, cognitive rehabilitation

Institute of Work, Health and Organizations, University of Nottingham, UK

\section{Corresponding author:}

Roshan das Nair, B09, IWHO, International House, Jubilee Campus, University of Nottingham, Nottingham NG8 1BB, UK Email: roshan.nair@nottingham.ac.uk 


\section{Introduction}

Memory impairments are one of the most common cognitive deficits reported by people who have multiple sclerosis $(40-60 \%),{ }^{1}$ traumatic brain injury $(54-84 \%)^{2}$ and stroke (about $\left.60 \%\right)^{3}{ }^{3}$ These memory problems are persistent, debilitating and frustrating, both to the patients and their carers ${ }^{4}$ and are difficult to treat. The safety of such patients can be compromised by memory deficits, making them vulnerable citizens in the home, community and work settings. Memory deficits may also affect the manner and extent to which such patients, who usually have other comorbid conditions, engage with other interventions or rehabilitation. Memory problems consequently can have a devastating effect on the psychological well-being of individuals and others around them, ${ }^{5}$ and have significant long-term effects for patients and their families.

Katz et al. ${ }^{6}$ defined cognitive rehabilitation as 'a systematically applied set of medical and therapeutic services designed to improve cognitive functioning and participation in activities that may be affected by difficulties in one or more cognitive domains' (p. 2). Memory rehabilitation is a specialized component of cognitive rehabilitation. The cognitive rehabilitation literature is divided on what strategies work best for people with memory problems. These strategies include restoration (restitution), which aims to improve a specific cognitive function, possibly by forcing a damaged neural circuit to work again, through regeneration or unmasking of silent synapses; or compensation, which focuses on adapting to the presence of a cognitive deficit, possibly by employing other undamaged circuits to perform a task or function.? Clinically, restitution is attempted by repeated drill and practice on focused, discrete aspects of a cognitive function, while compensation is achieved by teaching patients to use strategies to adapt to the problem, with the use of prosthetics or environmental manipulation. ${ }^{8}$ While restitution has been found to be useful in some domains of memory function, such as verbal memory performance (word lists), ${ }^{9}$ it has generally not been viewed favourably in the memory rehabilitation literature. However, as Evans ${ }^{10}$ asserted, this view is 'largely based on the absence of evidence rather than evidence of absence of an effect of restitution oriented therapies' (p. 520).

While there has been substantial growth in the number of memory rehabilitation studies, ${ }^{11}$ systematic reviews of the effectiveness of memory rehabilitation following stroke, ${ }^{12}$ multiple sclerosis ${ }^{13}$ and traumatic brain injury ${ }^{14}$ have concluded that there is insufficient evidence to support or refute the use of such rehabilitation strategies. These reviews have pointed to the poor quality and quantity of randomized trials in this area, and the diverse manner in which outcomes are assessed, leading to difficulties in converging data into a meta-analysis. Metaanalyses are particularly warranted in memory rehabilitation given the need for large participant numbers in individual trials and the long duration and intensity of interventions, which sometimes lead to attrition. A recent meta-analysis ${ }^{15}$ examining the effectiveness of cognitive rehabilitation following acquired brain injury concluded that the results for memory rehabilitation were 'mixed and weak' ( $p$. 33). This conclusion was contested by Cicerone et al., ${ }^{16}$ who claimed that there was 'substantial evidence' (p. 519) to support interventions for memory. There are several reasons why this difference in results has emerged, and one of them relates to the type of outcomes considered by the various studies. The diversity of outcomes is not limited to the types of individual tests employed, but also the International Classification of Function ${ }^{17}$ domains they tap, with most only assessing impairment with objective memory measures. As Wilson ${ }^{18}$ and Wade and Halligan ${ }^{19,20}$ have suggested, this form of assessment falls short of the aims and spirit of neuropsychological rehabilitation. Cognitive rehabilitation, Wilson ${ }^{18}$ suggested, 'should focus on real-life, functional problems, it should address associated problems such as mood or behavioural problems' ( $p$. 99). The discrepancies observed in recent metaanalytic studies suggest that the debate related to the effectiveness of memory rehabilitation is far from over.

The aim of this study was to compare the effectiveness of compensation and restitution memory rehabilitation strategies with a self-help control, on an ecologically valid measure of memory 
functioning. In addition, the effect of intervention on memory, mood, independence in activities of daily living and adjustment was examined. It was hypothesized that the intervention groups would produce better outcomes than the control group, and that compensation training would reduce memory failures in daily life more than restitution.

\section{Methods}

The study was advertised among clinicians and through charities, such as Headway, the Stroke Association and the Multiple Sclerosis Society. Posters were also placed in clinics and stroke clubs. Individuals were included if they were over the age of 18 , and reported memory problems due to a traumatic brain injury, stroke or multiple sclerosis; having been diagnosed at least one month prior to recruitment and having no previous diagnosis of brain damage or other severe disability. Diagnosis was verified by hospital or general practitioner records. Participants with mixed aetiologies were included to be representative of clinical practice. Participants were excluded if they did not speak English or lived more than 50 miles from Nottingham or Derby.

After informed consent was obtained, all potential participants underwent baseline assessments. These included assessment of language ability (Sheffield Screening Test for Acquired Language Disorders); ${ }^{21}$ pre-morbid intellectual level (National Adult Reading Test) ${ }^{22}$ memory (Rivermead Behavioural Memory Test Extended version, ${ }^{23}$ Spatial and Digit Span subtests of the Wechsler Memory Scale Third Edition ${ }^{24}$ and Doors and People: a test of visual and verbal recall and recog-nition ${ }^{25}$ ); executive abilities (Trail Making Test ${ }^{26}$ and Stroop Neuropsychological Screening Test - Victoria version $^{27}$ ); mood (General Health Questionnaire$12^{28}$ ) and disability (Nottingham Extended Activities of Daily Living Scale ${ }^{29}$ ). People with uncorrected visual or hearing impairments which prevented them from completing the assessments were excluded; as were those who did not have a demonstrable memory deficit, defined as an overall profile score of $>1$ on the Rivermead Behavioural Memory Test Extended version.
Participants were informed that their allocation to the type of programme was to be determined by chance. However, if they were allocated to the selfhelp programme, they had the option of attending an intervention group after they completed the second follow-up.

Randomization was conducted by an independent randomization centre. A computer-generated random number sequence was prepared in advance of the study. Block randomization was used with each cluster comprising four participants, who were able to attend a group at the same time and place. Participants were randomized to one of three programmes: restitution, compensation or self-help. The intervention groups were conducted by research assistants who were trained by the lead author, and all three programmes were documented in a manual to ensure consistency of delivery of sessions across time and groups. The format and duration of all three programmes were comparable. Each session lasted approximately one and a half hours, with a 10-15 minute break. All sessions began with a summary of the previous session, a plan for the current session, and ended with a review of the session, assignment of homework and a preview of the next session. There were 10 sessions in each programme. Homework provided participants with an opportunity to translate what was learned in sessions to their everyday life and to practise the use of memory aids and relaxation strategies. Travel expenses were offered to all participants.

The treatment manuals were developed on the basis of pre-existing workbooks, ${ }^{30}$ published studies and by consulting practitioners. Participants in both memory intervention programmes were taught the use of internal memory aids and errorless learning techniques. In addition, those in the compensation group were taught how to use external memory aids. The restitution group engaged in exercises to practise encoding and retrieval, which also included attention retraining exercises, such as letter and number cancellation tasks. People were also taught how to encode specific information using the Who, What, Where, When, Why and How questions. The selfhelp group were not taught any memory strategies, but were taught relaxation techniques and ways in which they could cope with their condition. In order 
to ensure that there was not a substantial amount of 'memory' input in the self-help group, and to ensure that the two intervention groups had equal proportions of memory components, which only differed qualitatively (one focusing on restitution and the other on compensation), independent observational time-sampling was conducted on all programmes.

Follow-up assessments were conducted five and seven months after randomization, by an assessor blind to the group allocation, who informed participants at the beginning of the assessment session that they were not to disclose any information about the programmes they attended.

The primary outcome measure was the Everyday Memory Questionnaire. ${ }^{31}$ This is a unitary, selfadministered scale which measures slips in 'normal' memory function (e.g. forgetting where you have put something). It has good face validity, assesses reallife situations and is used in clinical practice. The secondary outcome measures were the
Rivermead Behavioural Memory Test - Extended version, General Health Questionnaire-12 and Nottingham Extended Activities of Daily Living Scale. In addition, the Internal and External Memory Aids Questionnaires (based on the Memory Aids Questionnaire $^{32}$ ) were completed to assess the use of memory aids. The Wimbledon Self Report Scale ${ }^{33}$ was included to assess emotional state and the Mental Adjustment to Brain Damage scale (modified from the Mental Adjustment to Cancer scale) ${ }^{34}$ to assess psychological adjustment.

\section{Results}

Participants were recruited between May 2004 and August 2008. Of the 142 patients referred, 25 declined to take part in the study, 32 did not reply to the invitation to take part, 9 did not meet the inclusion criteria, and 76 were assessed (see Figure 1 for

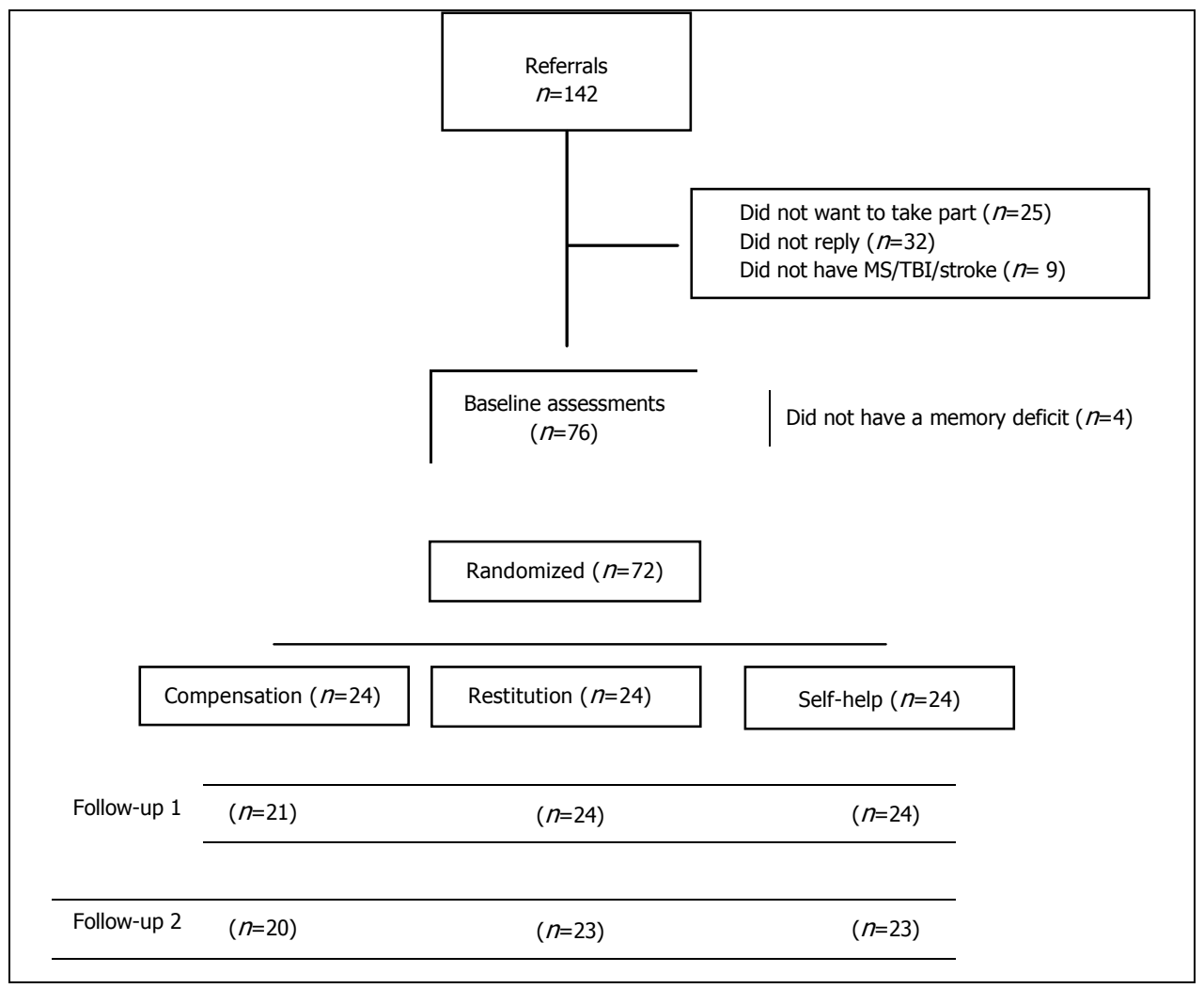

Figure I. Flowchart showing flow of participants through the trial. MS, multiple sclerosis; TBI, traumatic brain injury. 
details). Four participants were excluded as they did not have a demonstrable memory deficit, leaving 72 who were randomly allocated to one of the three programmes.

Participant characteristics are shown in Table 1. The groups were well matched on baseline characteristics.

An intention-to-treat analysis was used, so that all participants' outcomes were considered regardless of their attendance at groups. Analysis was initially conducted on those with complete outcome data. Then a sensitivity analysis was conducted in which missing outcomes were replaced with the last observation carried forward. As there were three assessments, the sample size was small and most of the scales are ordinal, the area under the curve was calculated as a summary measure. ${ }^{35}$ Results are shown in Tables 2 and 3.

There was a significant difference between the groups on the Internal Memory Aids Questionnaire $(\boldsymbol{P}=0.002)$. In addition the difference on the External Memory Aids Questionnaire approached significance $(\boldsymbol{P}=0.07)$ as did the Wimbledon Self Report Scale when using the last observation carried forward to replace missing outcome data $(\boldsymbol{P}$ $=0.055)$. There were few differences between the results based on those with complete outcomes and when missing outcome data was replaced.

In order to determine where the significant differences occurred a Mann-Whitney $\boldsymbol{U}$-test was used to compare the groups in pairs on the Internal and External Memory Aids Questionnaires and the Wimbledon Self Report Scale for those with completed outcomes. These showed significant differences between compensation and self-help groups on the Internal Memory Aids Questionnaire at both five months $(\boldsymbol{P}=0.006)$ and seven months $(\boldsymbol{P}=$ $0.010)$ and on the External Memory Aids Questionnaire at seven months $(\boldsymbol{P}=0.049)$. There were significant differences between the restitution and self-help groups on the Internal Memory Aids Questionnaire at five months $(\boldsymbol{P}=0.002)$ and seven months $(\boldsymbol{P}=0.011)$. There was a significant difference between the compensation and restitution groups on the Wimbledon Self Report Scale at seven months $(\boldsymbol{P}=0.013)$, indicating that those in the compensation group had a better emotional state than those in the restitution group.

\section{Discussion}

The results indicate there were no statistically significant differences between restitution and compensation treatment groups and a self-help control group in self-reported memory problems in daily life. However, both restitution and compensationbased memory rehabilitation programmes appeared to lead to an increased use of memory aids. These results suggest that participants learned to use the memory strategies that they were taught in the two memory intervention groups. It is possible that the greater differences seen in the use of internal memory aids was because these had not been taught as part of clinical practice, whereas participants may have previously been taught to use some external memory aids and therefore the effect of intervention on these was less. The effects persisted beyond the end of the intervention, which suggests they continued to be used. It is possible that a consolidation period is required before memory aids can be used efficiently. This is consistent with the aims of the intervention, which was to provide participants with strategies to deploy, depending on their preferences and according to their needs. Participants in the restitution group also developed the use of compensatory strategies. Dirette and colleagues ${ }^{36}$ also observed that $80 \%$ of those trained in restorationtype tasks also went on to develop the use of compensatory strategies spontaneously.

The lack of significant differences between groups on the primary outcome measure, the Everyday Memory Questionnaire, may reflect the scoring method used. In this questionnaire items are rated according to the frequency of occurrence and no consideration is given to the importance of the item to the respondent. It may be that the frequency of the forgetting did not change substantially but the use of strategies may have reduced the inconvenience caused; for example, still forgetting to do something, but doing it when prompted by a pre-set reminder on a mobile phone. It may also be that the aspects of memory assessed on the questionnaire do not adequately reflect the daily life activities that change with treatment.

One interesting observation was that the outcome of the restitution group was similar to the compensation group. Although it is difficult to 
Table I. Demographic and baseline characteristics of study participants

\begin{tabular}{|c|c|c|c|c|c|c|c|}
\hline & & Inter & & & & & \\
\hline & & Compe & tion $n=24$ & Restit & $n n=24$ & Self- $h$ & $\eta=24$ \\
\hline & & $n$ & $\%$ & $n$ & $\%$ & $n$ & $\%$ \\
\hline Diagnosis & Traumatic brain injury & 8 & 33 & 5 & 21 & 3 & 13 \\
\hline & Stroke & 4 & 17 & 2 & 1 & 11 & 46 \\
\hline & Multiple sclerosis & 12 & 50 & 17 & 71 & 10 & 42 \\
\hline Gender & Male & 9 & 38 & 9 & 38 & 14 & 58 \\
\hline & Female & 15 & 63 & 15 & 63 & 10 & 42 \\
\hline Employment & Full-time & 6 & 25 & 7 & 29 & 7 & 29 \\
\hline & Part-time & 5 & 21 & 1 & $<1$ & 4 & 17 \\
\hline & Unemployed & 12 & 50 & 16 & 67 & 12 & 50 \\
\hline & Missing & 1 & $<1$ & 0 & 0 & 1 & $<1$ \\
\hline Living arrangements & With other/carer & 13 & 54 & 15 & 63 & 18 & 42 \\
\hline & Alone & 8 & 33 & 4 & 17 & 3 & 13 \\
\hline & With other as carer & 0 & 0 & 4 & 17 & 0 & 0 \\
\hline & Other & 2 & 1 & 1 & $<1$ & 2 & 1 \\
\hline & & Mean & SD & Mean & SD & Mean & SD \\
\hline Age in years & & 49.5 & 9.0 & 42.9 & 8.9 & 50.6 & 11.3 \\
\hline Time since diagnosis/ & ry (months) & 127.7 & 125.4 & 82.6 & 86.6 & 58.8 & 49.5 \\
\hline Education in years & & 13.5 & 2.6 & 13.6 & 2.6 & 12.4 & 2.1 \\
\hline National Adult Readin & est - Pre-morbid IQ & 108.3 & 11.1 & 105.0 & 10.0 & 109.9 & 8.9 \\
\hline $\begin{array}{l}\text { Sheffield Screening te } \\
\text { Disorders }\end{array}$ & or Acquired Language & 19.1 & 0.9 & 19.1 & 1.1 & 18.5 & 1.6 \\
\hline WAIS III Digit Span S & d score & 10.1 & 2.5 & 8.6 & 2.5 & 8.6 & 2.8 \\
\hline WAIS III Spatial span & & 9.5 & 2.6 & 9.1 & 3.7 & 8.8 & 2.1 \\
\hline Doors and People Ov & & 10.4 & 9.2 & 6.6 & 2.8 & 6.2 & 2.9 \\
\hline Trail Making (B-A) & & 56.4 & 30.0 & 51.2 & 34.2 & 88.3 & 95.0 \\
\hline Stroop time (colour-w & & 11.7 & 7.3 & 15.1 & 11.5 & 20.0 & 17.0 \\
\hline Stroop errors (colour- & & 0.3 & 0.8 & 0.8 & 1.2 & 0.3 & 1.2 \\
\hline
\end{tabular}

confidently assert the usefulness of restitution, as the differences between intervention and self-help groups were not statistically significant, these results highlight the potential use of restitution as a treatment strategy. Restitution may be an appropriate adjunct to compensation-focused rehabilitation programmes.

There were no significant effects of intervention on adjustment or independence in activities of daily living. This may be due to insufficient power of this study to detect differences. There were, however, improvements in adjustment across all groups, as measured on the Mental Adjustment to Brain Damage scale. This is consonant with findings which observed reduction in some emotional adjustment difficulties, even years after injury. ${ }^{37}$ Such improvements may be due to the non-specific effects of attending a group. There was, however, a difference in mood between the restitution and compensation groups, as assessed on the Wimbledon Self Report Scale. This could be a chance finding or it could be that the use of compensation strategies 
Table 2. Descripstive statistis for outcome assessments

\begin{tabular}{|c|c|c|c|c|c|c|c|c|c|c|}
\hline \multirow[t]{2}{*}{ Outcome variable } & \multirow{2}{*}{$\begin{array}{l}\text { Group } \\
\text { Time }\end{array}$} & \multicolumn{3}{|c|}{ Compensation } & \multicolumn{3}{|c|}{ Restitution } & \multicolumn{3}{|c|}{ Self-help } \\
\hline & & n & Man & SD & a & Mean & SD & $n$ & Mean & SD \\
\hline \multirow[t]{3}{*}{ Everyday Memory Questionraire } & Baseline & 21 & 397 & 21.0 & 23 & 47.9 & 25.2 & 23 & 45.5 & 24.1 \\
\hline & 5 months & 21 & 37.1 & 18.8 & 23 & 42.6 & 24.9 & 23 & 42.7 & 24.3 \\
\hline & 7 montts & 21 & 366 & 20.2 & 23 & 41.0 & 25.8 & 23 & 44.1 & 27.2 \\
\hline \multirow[t]{3}{*}{ Rivermead Behavioural MenoryTes:- Extended } & Baseline & 24 & 221 & 78 & 24 & 24.0 & 8.0 & 24 & 21.0 & 6.7 \\
\hline & 5 months & 24 & 233 & 100 & 24 & 24.6 & 7.9 & 24 & 22.9 & 7.1 \\
\hline & 7 months & 24 & 252 & 8.8 & 24 & 26.1 & 7.5 & 24 & 24.6 & 7.7 \\
\hline \multirow[t]{3}{*}{ General Health Quassisnnaire-12 } & Baseline & 24 & 38 & 3.6 & 24 & 4.2 & 3.6 & 24 & 2.5 & 3.1 \\
\hline & 5 months & 24 & 3.1 & 3.3 & 24 & 4.1 & 37 & 24 & 3.6 & 3.8 \\
\hline & 7 months & 24 & 32 & 3.7 & 24 & 5.8 & 4.3 & 24 & 3.2 & 3.9 \\
\hline \multirow[t]{3}{*}{ Nottingham Extended Activities of Daily Living } & Baseline & 23 & 51.7 & 125 & 22 & 49.1 & 11.7 & 23 & 46.3 & 12.7 \\
\hline & 5 months & 22 & 513 & 128 & 22 & 48.3 & 12.7 & 22 & 45.1 & 12.6 \\
\hline & 7 montts & 23 & 513 & 13.6 & 22 & 50.3 & 11.0 & 23 & 48.2 & 113 \\
\hline \multirow[t]{2}{*}{ Internal Memory Aids Questionnaire } & 5 montts & 18 & 245 & 5.2 & 19 & 25.4 & 47 & 20 & 19.1 & 6.2 \\
\hline & 7 months & 19 & 23.7 & 5.2 & 20 & 24.5 & 6.3 & 20 & 19.8 & 5.6 \\
\hline \multirow[t]{2}{*}{ External Memory Aids Questionnaire } & 5 montts & 16 & 287 & 82 & 19 & 28.8 & 5.9 & 20 & 26.3 & 5.6 \\
\hline & 7 months & 19 & 300 & 9.6 & 20 & 27,7 & 4.9 & 20 & 26.0 & 4.2 \\
\hline \multirow[t]{2}{*}{ Wimbledon Seff Repart 5cale } & 5 months & 19 & 18.1 & 4.4 & 20 & 22.3 & 7.6 & 20 & 23.2 & 8.2 \\
\hline & 7 months & 19 & 177 & 4.1 & 20 & 23.4 & 7.3 & 20 & 22.7 & 8.6 \\
\hline \multirow[t]{2}{*}{ MentalAdjustmen: to Brain Injury } & 5 months & 18 & 972 & 208 & 20 & 100.1 & 11.2 & 20 & 102.9 & 10.0 \\
\hline & 7 months & Ie & 103.7 & 8.5 & 20 & 104.9 & 10.5 & 20 & 104.5 & 8.6 \\
\hline
\end{tabular}


Table 3. Comparison of intervention groups on area under the curve

\begin{tabular}{|c|c|c|c|c|c|}
\hline \multirow[b]{2}{*}{ Outcome variable } & \multirow[b]{2}{*}{ Intervention } & \multicolumn{2}{|c|}{$\begin{array}{l}\text { Analysis of those } \\
\text { with complete } \\
\text { outcomes }\end{array}$} & \multicolumn{2}{|c|}{$\begin{array}{l}\text { Analysis with last } \\
\text { observation carried } \\
\text { forward }\end{array}$} \\
\hline & & $n$ & $P$ & $n$ & $P$ \\
\hline \multirow[t]{3}{*}{ Everyday Memory Questionnaire } & Compensation & 21 & 0.964 & 24 & 0.976 \\
\hline & Restitution & 23 & & 24 & \\
\hline & Self-help & 23 & & 24 & \\
\hline \multirow[t]{3}{*}{ Rivermead Behavioural Memory Test - Extended } & Compensation & 24 & 0.780 & 24 & 0.780 \\
\hline & Restitution & 24 & & 24 & \\
\hline & Self-help & 24 & & 24 & \\
\hline \multirow[t]{3}{*}{ General Health Questionnaire-12 } & Compensation & 24 & 0.124 & 24 & 0.123 \\
\hline & Restitution & 24 & & 24 & \\
\hline & Self-help & 24 & & 24 & \\
\hline \multirow[t]{3}{*}{ Extended Activities of Daily Living } & Compensation & 23 & 0.877 & 24 & 0.440 \\
\hline & Restitution & 22 & & 24 & \\
\hline & Self-help & 23 & & 24 & \\
\hline \multirow{3}{*}{ Internal Memory Aids Questionnaire } & Compensation & 18 & $0.002^{*}$ & 24 & $0.002^{*}$ \\
\hline & Restitution & 19 & & 24 & \\
\hline & Self-help & 20 & & 24 & \\
\hline \multirow[t]{3}{*}{ External Memory Aids Questionnaire } & Compensation & 18 & 0.070 & 24 & 0.070 \\
\hline & Restitution & 19 & & 24 & \\
\hline & Self-help & 20 & & 24 & \\
\hline \multirow[t]{3}{*}{ Wimbledon Self Report Scale } & Compensation & 19 & 0.154 & 24 & 0.055 \\
\hline & Restitution & 20 & & 24 & \\
\hline & Self-help & 20 & & 24 & \\
\hline \multirow[t]{3}{*}{ Mental Adjustment to Brain Injury } & Compensation & 19 & 0.839 & 24 & 0.771 \\
\hline & Restitution & 20 & & 24 & \\
\hline & Self-help & 20 & & 24 & \\
\hline
\end{tabular}

${ }^{*}$ Significant at $P<0.01$.

puts fewer demands on the individuals themselves, which is less stressful. In contrast, restitution approaches may require more active attempts by participants to encode information to compensate for their memory problems and this may be more emotionally demanding. This requires further evaluation.

The study design meant it was not possible to ascertain the effect of attending a group. To this extent, future studies should compare memory rehabilitation with a no intervention control instead of a self-help control group, to determine the effect of emotional support on outcomes. A limitation of this study is the clinical heterogeneity of the sample. The aim was to analyse 'progressive' and 'nonprogressive' subgroups, but this was not done due to the limited sample size. However in clinical practice people receive memory rehabilitation in mixed aetiology groups and there was little evidence of a differential effect of memory rehabilitation according to diagnosis at the time the study was designed.

Given the lack of conclusive evidence for memory rehabilitation, it seems that further randomized 
controlled trials of memory rehabilitation programmes would be useful.

\section{Clinical messages}

- There was limited evidence of effectiveness of memory rehabilitation in people with acquired brain injuries, when evaluated using a randomized trial.

- Patients tended to use more memory aids when specifically taught to use them, but it is unclear whether this results in reduced memory failures.

- Memory rehabilitation had limited impact on mood, adjustment or independence of activities of daily living.

\section{Author contributions}

RdN and NBL conceived the study. RdN obtained ethical approval and managed the study under the supervision of NBL. Data analyses was conducted by RdN and NBL, and both authors contributed to the preparation of the manuscript.

\section{Ethics approval}

Ethical approval was obtained from Nottingham Research Ethics Committee 1 in May 2004.

\section{Patient consent}

Obtained.

\section{Acknowledgements}

We would like to thank Emily Bennett, Philippa Blythe, Niki Chouliara, Jo Darby, Alex Forman, Hugh Hawthorne, Paul Ince, Eirini Kontou, Georgia Lykomitru, Jacqui Mhizha-Murira, Marie Claire O'Brian, Kate Radford, Alana Tooze, and Kristina Vella, for assistance with running groups, conducting assessments, and feedback interviews. We would also like to thank Prof. Cees van der Eijk, Drs Jabulani Sithole, Jonathan Stirk, Ruth Parry and Shirley Thomas for their advice on statistics, research design and data analysis. Finally, we are indebted to all those who referred participants to the study and all our participants.

\section{Conflict of interest}

None.

\section{Funding}

The research was supported by grants from The Stroke Association, Remedi (2006/05), Universities UK (Overseas Research Students Award Scheme), and the University of Nottingham.

\section{References}

1. Rao SM. Neuropsychology of multiple sclerosis. Curr Opin Neurol 1995; 8: 216-220.

2. McKinlay WW and Watkiss AJ. Cognitive and behavioural effects of brain injury. In: Rosenthal M, Griffith ER, Bond M, et al. (eds) Rehabilitation of the adult and child with traumatic brain injury, third edition. Philadelphia, PA: Davis Company, 1999, pp. 74-86.

3. Doornhein $\mathrm{K}$ and de Haan EHF. Cognitive training for memory deficits in stroke patients. Neuropsychol Rehabil 1998; 8: 393-400.

4. Williamson DJG, Scott JG and Adams RL. Traumatic brain injury. In: Adams RL, Parsons, OA, Culbertson JL and Nixon SJ (eds) Neuropsychology for clinical practice: etiology, assessment, and treatment of common neurological disorder. Washington, DC: American Psychological Association, 1996, pp. 9-64.

5. Skeel RL and Edwards S. The assessment and rehabilitation of memory impairments. In: Johnstone B and Stonnington $\mathrm{HH}$ (eds) Rehabilitation of neuropsychological disorders: a practical guide for rehabilitation professionals. Philadelphia, PA: Psychology Press, Taylor \& Francis, 2001, pp. 53-85.

6. Katz DI, Ashley MJ, O'Shanick GJ and Connors SH. Cognitive rehabilitation: the evidence, funding and case for advocacy in brain injury. McLean, VA: Brain Injury Association of America, 2006.

7. Held JM and Pay T. Recovery of function after brain damage. In: Cohen H (ed.) Neuroscience for rehabilitation, second edition. Philadelphia, PA: Lippincott Williams \& Wilkins, 1999, pp. 419-440.

8. Robertson $\mathrm{IH}$ and Murre JMJ. Rehabilitation of brain damage: Brain plasticity and principles of guided recovery. Psy-chol Bull 1999; 125: 544-575.

9. Hildebrandt H, Bussmann-Mork B and Schwendemann G. Group therapy for memory impaired patients: a partial remediation is possible. J Neurol 2006; 253: 512-519.

10. Evans JJ. Memory rehabilitation: should we be aiming for restoration or compensation? Commentary on Hildebrandt 
$\mathrm{H}$ et al. Group therapy for memory impaired patients: A partial remediation is possible. J Neurol 2006; 253: 520-521.

11. Cicerone K, Dahlberg C, Malec JF, et al. Evidence-based cognitive rehabilitation: updated review of the literature from 1998 through 2002. Arch Phys Med Rehabil 2005; 86: $1681-1692$.

12. das Nair R and Lincoln NB. Cognitive rehabilitation for memory deficits following stroke. Cochrane Database of Systematic Reviews 2007. Issue 3. Art. No.: CD002293. DOI: 10.1002/14651858.CD002293.pub2.

13. das Nair R, Ferguson H, Stark D and Lincoln NB. Memory rehabilitation in multiple sclerosis. Cochrane Database Syst Rev (in press).

14. Carney N, Chesnut R, Maynard H, Mann NC, Patterson P and Helfland M. Effect of cognitive rehabilitation on outcomes for persons with traumatic brain injury: a systematic review. J Head Trauma Rehabil 1999; 14: 277-307.

15. Rohling ML, Faust ME, Beverley B and Demakis G. Effectiveness of cognitive rehabilitation following acquired brain injury: A meta-analytic re-examination of the Cicerone et al.'s (2000, 2005) systematic reviews. Neuropsychology 2009; 23: 20-39.

16. Cicerone KD, Langenbahn DM, Braden C, et al. Evidencebased cognitive rehabilitation: Updated review of the literature from 2003 through 2008. Arch Phys Med Rehabil 2011; 92: 519-530.

17. World Health Organization. International Classification of Functioning, Disability and Health. Geneva: World Health Organization, 2001.

18. Wilson BA. Towards a comprehensive model of cognitive rehabilitation. Neuropsychol Rehabil 2002; 12: 97-110.

19. Wade DT and Halligan PW. New wine in old bottles: The WHO ICF as an explanatory model of human behaviour. Clin Rehabil 2003; 17: 349-354.

20. Wade DT and Halligan PW. Do biomedical models of illness make for good healthcare systems? BMJ 2004; 329 : 1398-1401.

21. Syder D, Body R, Parker M and Boody M. Sheffield Screening Test for Acquired Language Disorders. Windsor: NFER-Nelson, 1993.

22. Nelson HE and Willison J. National Adult Reading Test. Chiswick: NFER-Nelson, 1991.

23. Wilson BA, Clare L, Baddeley AD, Cockburn J, Watson P and Tate R. The Rivermead Behavioural Memory Test -
Extended Version. Bury St. Edmunds: Thames Valley Test Company, 1999.

24. Wechsler D, Wycherley RJ, Benjamin L, Crawford J and Mockler D. Wechsler Memory Scale, third edition. London: The Psychological Corporation Ltd, 1998.

25. Baddeley AD, Emslie H and Nimmo-Smith I. Doors and people: a test of visual and verbal recall and recognition. Bury St. Edmunds: Thames Valley, 1994.

26. Reitan R. Validity of the Trail Making Test as an indication of organic brain damage. Percept Motor Skills 1958; 8: 271-276.

27. Regard M. Cognitive rigidity and flexibility: A neuropsychological study. University of Victoria, British Columbia, 1981.

28. Goldberg RJ and Williams. PA. User's guide to the General Health Questionnaire. Windsor: NFER-Nelson, 1988.

29. Nouri FM and Lincoln NB. An extended activities of daily living scale for stroke patients. Clin Rehabil 1987; 1: 233-238.

30. Powell $\mathrm{T}$ and Malia K. The brain injury work book, exercises for cognitive rehabilitation. Bicester: Speechmark Publishing, 2003.

31. Sunderland A, Harris JE and Baddeley AD. Do laboratory tests predict everyday memory? A neuropsychological study. J Verbal Learning Verbal Behav 1983; 22: 341-357.

32. Wilson BA and Moffat N. Clinical management of memory problems. Bury St Edmunds: Chapman \& Hall, 1984.

33. Coughlan A and Storey P. The Wimbledon Self-Report Scale: emotional and mood appraisal. Clin Rehabil 1988: 2: 207-213.

34. Watson M, Greer S, Young J, Inayat Q, Burgess C and Robertson B. Development of a questionnaire measure of adjustment to cancer: the MAC scale. Psychol Med 1988; 18: 203-209.

35. Matthews JN, Altman DG, Campbell MJ and Royston P. Analysis of serial measurements in medical research. BMJ 1990; 300: 230-235.

36. Dirette DK, Hinojosa $\mathbf{J}$ and Carnevale GJ. Comparison of remedial and compensatory interventions for adults with acquired brain injuries. J Head Trauma Rehabil 1999; 14: 595-601.

37. Ruff RM and Niemann H. Cognitive rehabilitation versus day treatment in head injured adults: is there an impact on emotional and psychosocial adjustment? Brain Inj 1990; 4: 339-347. 